\title{
Renal Crisis Due to Intimal Hyperplasia in a Patient with Mixed Connective Tissue Disease (MCTD) Accompanied by Pulmonary Hypertension
}

\author{
Toru Yamaguchi, Shiro Ohshima, Toshio Tanaka, Satoshi Tsukada, Masato Matsushita, Satoshi Kohmo, \\ Toru KANZAKI and Yukihiko SAEKI
}

\begin{abstract}
We report the case of a young female patient with mixed connective tissue disease (MCTD). She had marked pulmonary hypertension (PH) without lung fibrosis. She developed renal crisis after delivery by caesarean section. Renal biopsy revealed severe renal intimal hyperplasia with mild glomerular changes. The combination of intravenous pulse high-dose corticosteroid and cyclophosphamide (CPA) infusion and subsequent corticosteroid oral administration rescued her from renal crisis. This suggests that the possibility of co-incident renal intimal hyperplasia should be considered in patients with MCTD accompanied by PH. In addition, there might be some clinical benefit in combining high-dose corticosteroid with CPA infusion in the treatment of renal crisis due to intimal hyperplasia in MCTD.

(Internal Medicine 40: 1250-1253, 2001)
\end{abstract}

Key words: sclerodermatous renal crisis, immunosuppressive therapy

\section{Introduction}

Mixed connective tissue disease (MCTD), originally described by Sharp et al (1), is an overlapping syndrome characterized by the combination of clinical features of systemic lupus erythematosus (SLE), systemic sclerosis (or scleroderma), and polymyositis/dermatomyositis, and the presence of high titers of antibodies to $U_{1}$ RNP. In the initial description of MCTD, the incidence of renal involvement in MCTD was considered to be rare (2), however, cumulative evidence has suggested that renal involvement is not so rare in MCTD (3-5). It is suggested that more than 10 percent of patients with MCTD develop renal diseases $(3,4)$. Among them, membranous glomerulonephritis is the most common and usually mild but can cause nephrotic syndrome (4). Diffuse proliferative glomerulonephritis is unusual in MCTD (4). Thus, it is believed that the prognosis of renal involvement in MCTD is usually excellent. However, some patients develop sclerodermatous renal crisis, with abrupt onset of severe hypertension and renal dysfunction $(6,7)$ and the prognosis of these patients is usually quite poor.

For editorial comment, see p 1176.

\section{Case Report}

In June 1996, a 24-year-old Japanese woman first experienced Raynaud's phenomenon. In September, she had a high grade fever accompanied with facial erythema. The patient underwent a thorough medical examination at a local hospital and was found to be positive for antibodies to nuclear antigen (ANA). Then, she was referred to our hospital for further examination. The physician noted puffy hands with sclerodactyly accompanied by a digital pitting scar of left forefinger. In addition, laboratory studies revealed the presence of a high titer of antibodies to $U_{1} R N P$. Then, according to the diagnostic criteria of the Japanese MCTD Committee (8), she was diagnosed as having MCTD, based on the presence of Raynaud's phenomenon, swollen hands, a high titer of antibodies to $\mathrm{U}_{1} \mathrm{RNP}$, facial erythema for a SLE-like finding, and sclerodactyly for a scleroderma-like finding. However, since her clinical symptoms were not so severe, she was followed without any medication.

In January 2000, she had a low grade fever, the feeling of fatigue and generalized weakness. At the same time, she was found to be pregnant. In March, she complained of an exertional dyspnea. At that time, the doctor noted a mild elevation of Creactive protein (CRP) and thrombocytopenia but arterial blood oxygen saturation was normal. Then, the doctor assessed that the disease activity was increasing and started to administer a

From the Department of Molecular Medicine and Obstetrics Osaka University Medical School, Osaka

Received for publication March 29, 2001; Accepted for publication August 7, 2001

Reprint requests should be addressed to Dr. Yukihiko Saeki, the Department of Molecular Medicine, Osaka University Medical School, 2-2 Yamada-Oka, Suita, Osaka 565-0871 


\section{Renal Intimal Hyperplasia in MCTD}

low dose of corticosteroid. However, her symptoms, particularly exertional dyspnea became worse. On May 31, 2000 when she visited the doctor, she was suspected of marked pulmonary hypertension (PH) by ultrasonic cardiography (UCG) studies, and was admitted to our hospital urgently.

On admission, she was at 27 weeks and 4 days of gestation. Her blood pressure (BP) was elevated at 130-140 mmHg systolic and 100-110 $\mathrm{mmHg}$ diastolic. She showed severe Raynaud's phenomenon and her hands were markedly swollen. Laboratory studies disclosed red blood cell count $334 \times 10^{4}$ / $\mathrm{mm}^{3}$, hemoglobin $12.0 \mathrm{~g} / \mathrm{dl}$, white blood cell count 10,300 / $\mathrm{mm}^{3}$, platelet count $6.8 \times 10^{4} / \mathrm{mm}^{3}$, PT $97 \%$, APTT 31 seconds, fibrinogen $441 \mathrm{mg} / \mathrm{dl}$, FDP $1.60 \mu \mathrm{g} / \mathrm{ml}$, potassium $3.9 \mathrm{mEq} / \mathrm{l}$, sodium $140 \mathrm{mEq} / l$, chloride $107 \mathrm{mEq} / l$, urea nitrogen $10 \mathrm{mg} / \mathrm{dl}$ and creatinine $0.8 \mathrm{mg} / \mathrm{dl}$. The level of serum CRP was slightly increased to $0.4 \mathrm{mg} / \mathrm{dl}$. Glucose, liver enzymes, and bilirubin were normal. Arterial blood gas studies showed obvious respiratory alkalosis at an oxygen tension of $82.0 \mathrm{mmHg}$, carbon dioxide tension of $20.4 \mathrm{mmHg}$, bicarbonate level of $16.5 \mathrm{mEq} / \mathrm{l}$, $\mathrm{pH}$ of 7.518 , and base excess of $-4.6 \mathrm{mEq} / \mathrm{l}$. On immunological analysis, the serum immunoglobulin levels were IgG 1,210 $\mathrm{mg} / \mathrm{dl}, \mathrm{IgA} 87 \mathrm{mg} / \mathrm{dl}$, and IgM $73 \mathrm{mg} / \mathrm{dl}$. The anti-nuclear antibody titer was 1:2,560 with a speckled pattern, and serum was positive for anti- $\mathrm{U}_{1} \mathrm{RNP}$ antibody, but negative for anti-Sm, anti-Scl 70, and anti-dsDNA antibodies. The serum complement levels were $C_{3}$ of $110 \mathrm{mg} / \mathrm{dl}$ and $C_{4}$ of $12 \mathrm{mg} / \mathrm{dl}$. Neither immune complex nor cryoglobulin was detected. Both lupus anticoagulant and anti- $\beta 2$ glycoprotein I antibody were negative. Platelet-associated IgG (PA-IgG) was not increased. On urinalysis, severe proteinuria was noted. The chest X-ray showed a moderate cardiomegaly, predominantly the right ventricle, and an obvious enlargement of pulmonary artery size but no abnormal shadows in the lung field. The electric cardiography showed a marked right axis deviation. The Doppler UCG revealed a marked dilatation of the right ventricle in addition to a mild tricuspid regurgitation and the pulmonary arterial blood pressure was estimated as $56 \mathrm{mmHg}$ maximal systolic and $30 \mathrm{mmHg}$ on average by recording Doppler profiles of the tricupid regurgitation velocities as described previously $(9,10)$. Later, the elevation of the pulmonary arterial pressure was confirmed by right heart catheterization which was performed during the caesarean section. Pulmonary perfusion scin-

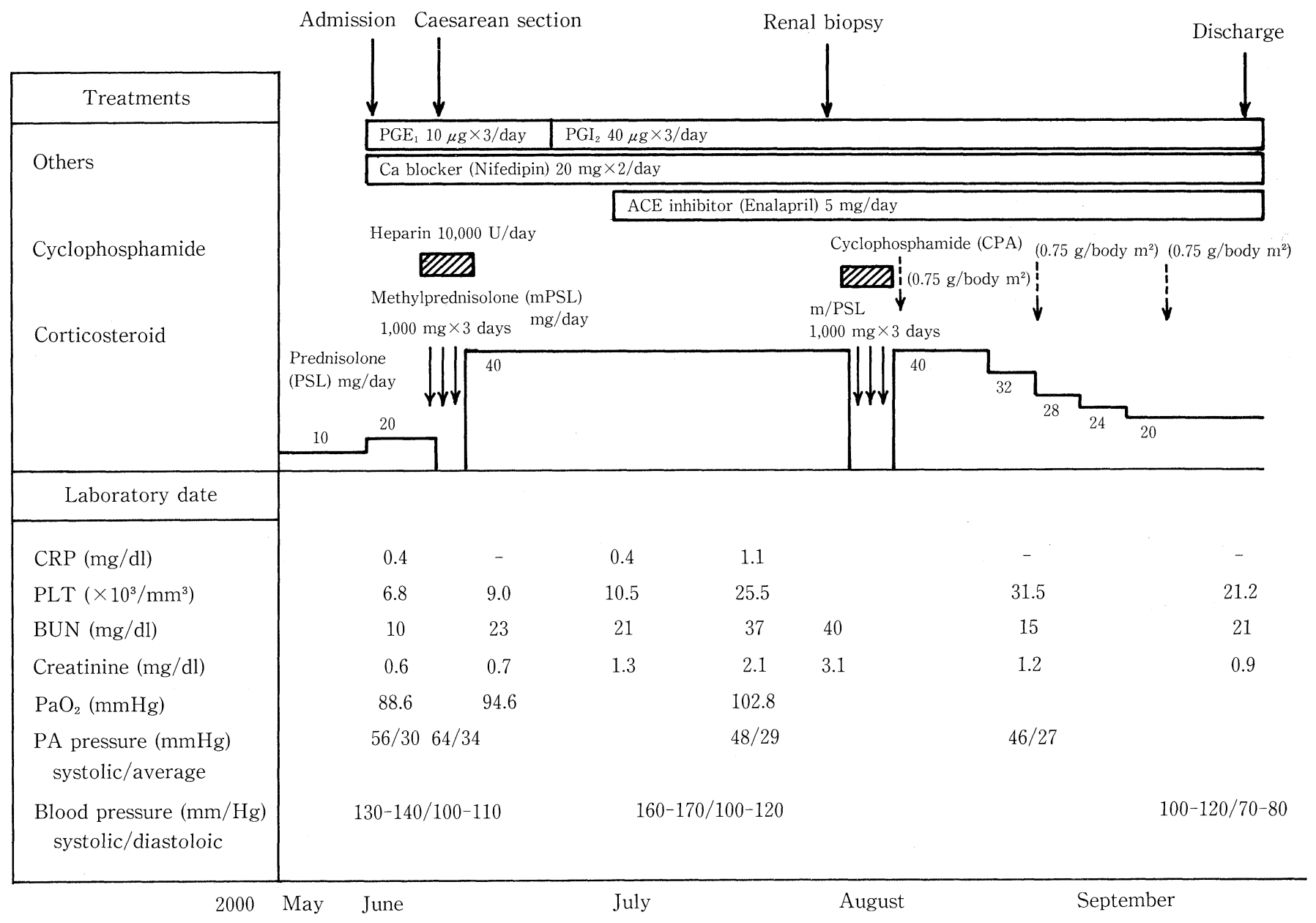

Figure 1. Clinical course. 
tigraphy showed no defects. Taken together with these conditions, due to the possibility of gestational toxemia, we consulted an obstetrician and decided to deliver her baby by caesarean section because of the high risk of both maternal and fetal mortality. In addition, we suspected that the disease activity of her MCTD was increasing because of the elevation in serum CRP and the presence of a low grade fever due to inflammatory reactions. Therefore, oral administration of highdose corticosteroid (methylprednisolone; mPSL $40 \mathrm{mg} /$ day) was started to control the disease activity of MCTD before the delivery.

The overall clinical course is summarized in Fig. 1. On June 3 , the delivery was performed successfully. PH did not become worse but was persistent. The BP gradually became elevated to $160-170 \mathrm{mmHg}$ systolic and $100-120 \mathrm{mmHg}$ diastolic. In addition, both serum urea nitrogen and creatinine levels were rapidly elevated, while proteinuria became less severe. Although her retina did not show any significant hypertensive changes and no fragmentation of red blood cells was observed, the serum activated renin concentration was markedly increased at $57.9 \mathrm{pg} / \mathrm{ml}$ (normal range, $10-30 \mathrm{pg} / \mathrm{ml}$ ). According to the diagnostic criteria described previously by Steen et al (11), the possibility of sclerodermatous renal crisis was suggested, thus we tried administration of the angiotensin coverting enzyme (ACE) inhibitor, enalapril, but there was no obvious decrease in $\mathrm{BP}$.

To elucidate the cause of the rapidly progressing renal failure, a kidney biopsy was performed on July 21,2000 with the patient's informed consent. As a result, regarding glomeruli, neither severe proliferative nor membranous glomerular changes were present but many glomeruli appeared collapsed. However, most of the interlobular arteries showed severe intimal hyperplasia (a representative histopathology is shown in Fig. 2). The histopathological features resembled those seen in sclerodermatous renal crisis.

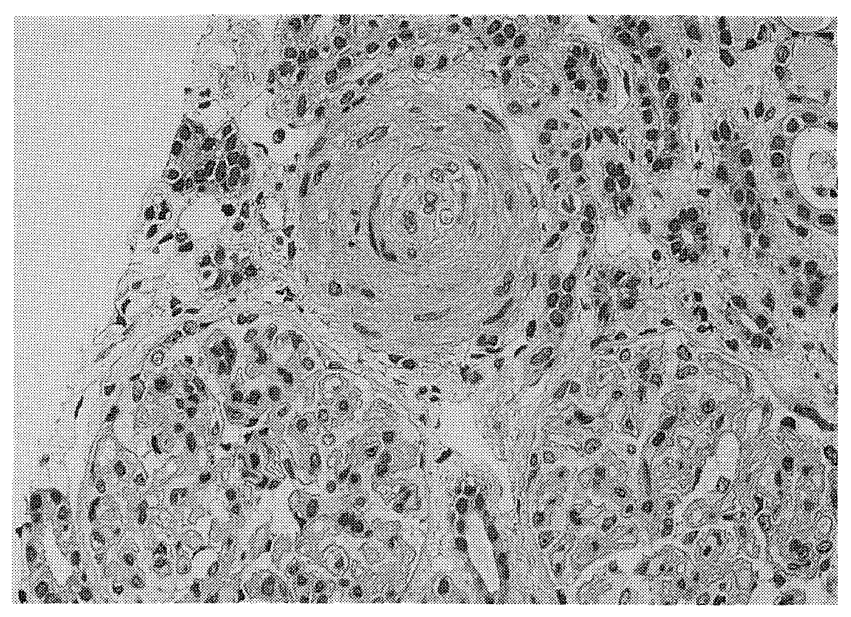

Figure 2. Interlobular artery with marked intimal hyperplasia (HE stain, $\times 200)$.
On July 25, due to progressive renal failure, we administered intravenous high-dose corticosteroid $(1,000 \mathrm{mg} /$ day of mPSL for 3 days) and started a monthly high dose $(0.75 \mathrm{~g} /$ body $\mathrm{m}^{2}$ ) of cyclophosphamide (CPA) infusion therapy with the patient's informed consent. Subsequently, we continued oral corticosteroid administration at a dose of $40 \mathrm{mg} / \mathrm{day}$ of mPSL. Within a month after starting the treatment, serum creatinine levels were gradually decreased and normalized until the middle of September. BP was also normalized. We succeeded in tapering the dose of corticosteroid and she was discharged on September 24 . There have not been any signs of a relapse to date.

\section{Discussion}

Here, we described a young female patient with MCTD. This case was characterized by the coincidence of marked $\mathrm{PH}$ and sclerodermatous renal crisis due to intimal hyperplasia. During the pregnancy, she developed $\mathrm{PH}$ which was worsening. It is suggested that approximately $4 \%$ of patients with MCTD develop PH and that the patients who show some typical clinical features of MCTD, such as Raynaud's phenomenon and the presence of a high titer of anti- $\mathrm{U}_{1} \mathrm{RNP}$ antibody, accompany $\mathrm{PH}$ more frequently. This patient showed such typical clinical features. Therefore, she possibly had PH asymptomatically before the pregnancy, although since the diagnosis of 1996, her MCTD had been well-controlled and she had no symptoms of PH. In addition, the conditions accompanied with pregnancy, such as hypervolemia and the hypercoagulating state, possibly worsened the PH. In fact, there is a case report describing that a patient with well-controlled MCTD developed progressive $\mathrm{PH}$ during pregnancy (12). Although the information on pregnacy in MCTD is limited, it is suggested that pregnancy does not deteriorate MCTD if it is well-controlled as described in a retrospective study (13). In the present case, MCTD might not have been inactive and was also involved in the worsening of $\mathrm{PH}$, because just before the development of $\mathrm{PH}$, her MCTD symptoms, such as Raynaud's phenomenon and swollen hands, became more severe and she also showed a low grade fever and an elevation of serum CRP, indicating the increasing disease activity of MCTD.

Parallel to the worsening $\mathrm{PH}$, she developed hypertension. At the beginning of her clinical course, marked proteinuria and thrombocytopenia were also noted. These findings suggested she had a gestational toxicemia, however, this was unlikely, because her hypertension was still worsening after the mandatory delivery by caesarean section and renal biopsy mainly showed a severe intimal hyperplasia of interlobular arteries, resembling that seen in scleroderma. These histopathological features were not compatible with those of gestational toxicemia. In pure gestatinal toxicemia, the primary sites of pathology are the glomerular endothelial cells, and the glomerular basement membrane and the extraglomerular blood vessels are intact. Although neither significant hypertensive retinal changes nor obvious microangiopathic signs, such as fragmentation of red blood cells, was observed, her serum activated renin concentration was markedly increased. According to the diagnostic 
criteria described previously by Steen et al (11), the rapid progressing hypertention with renal dysfunction was considered to be a sclerodermatous renal crisis. In fact, there have been a few case reports describing that some MCTD patients develop sclerodermatous renal crisis, with abrupt onset of severe hypertension and renal dysfunction $(6,7)$.

Regarding treatment, although there is no established treatment for sclerodermatous renal crisis caused by intimal hyperplasia, there have been some studies showing a clinical benefit of ACE inhibitors $(6,14)$. Therefore, we first tried the ACE inhibitor, enalapril, but there were no obvious effects. However, in the present patient the intensive anti-inflammatory and immunosuppressive therapy by a combination of pulse intravenous high-dose corticosteroid and CPA infusion rescued her from the renal crisis. Although at present, we cannot completely explain why such intensive anti-inflammatory and immunosuppressive therapy was effective in this patient, there are some issues to be considered. It is well-known that such intimal hyperplasia is also observed in small pulmonary arteries of MCTD patients as well as scleroderma patients with $\mathrm{PH}$ unaccompanied by lung fibrosis $(15,16)$. In the present patient, a marked $\mathrm{PH}$ was noted but no lung fibrosis and no defects in the pulmonary perfusion scintigraphy were observed. Taken together, it is suggested that her PH might have been caused by intimal hyperplasia, although we did not perform a lung biopsy. There have been some case reports describing the improvement of $\mathrm{PH}$ after treatment with corticosteroid and CPA in patients with $\operatorname{SLE}$ and MCTD $(17,18)$. Moreover, previously we also tried to treat MCTD patients with acute (or rapid progressing) $\mathrm{PH}$ using the combination of pulse intravenous high-dose corticosteroid and CPA infusion. In those trials, we found a subset of patients who showed a good response to this treatment (unpublished observations). This subset had some common clinical features such as the presence of inflammation indicated by mild elevation of CRP, and a relatively rapid progression of the disease. The present patient had similar clinical features.

Recently, there was an interesting study by Sawai et al (19), describing renal histopathological examinations of autopsy specimens from twenty-five MCTD patients, thirteen of whom died of PH. Most of those subjects had accompanying obvious renal intimal hyperplasia rather than severe proliferative or membranous glomerular changes in these MCTD patients. Taking the present findings together with their observations, it is suggested that the possibility of coincident renal intimal hyperplasia should be considered in patients with MCTD accompanied with $\mathrm{PH}$.

In conclusion, the present findings suggested that the possibility of coincident renal intimal hyperplasia in patients with MCTD accompanied by PH should be considered, and that there is a clinical benefit with combination therapy including highdose corticosteroid and CPA infusion for renal crisis due to intimal hyperplasia in MCTD. However, the results of a single case are not sufficient, and therefore subsequent studies are necessary.

\section{References}

1) Sharp GC, Irvin WS, Tan EM, Gould RG, Holman HR. Mixed connective tissue disease - An apparently distinct rheumatic disease syndrome associated with a specific antibody to an extractable nuclear antigen (ENA). Am J Med 52: 148-159, 1972.

2) Sharp GC, Irvin WS, May CM, et al. Association of antibodies to ribonucleoprotein and Sm antigens with mixed connective tissue disease, systemic lupus erythematosus and other rheumatic disease. N Engl J Med 295: 1149-1154, 1976.

3) Grant KD, Adams LE, Hess EV. Mixed connective tissue disease - A subset with sequential clinical and laboratory features. J Rheumatol 8: 587-598, 1981

4) Kitridou RC, Akmal M, Turkel SB, Ehresmann GR, Quismorio FP, Massry SG. Renal involvement in mixed connective tissue disease: a longitudinal cliniopathologic study. Semin Arthritis Rheum 16: 135-145, 1986.

5) Bennett RM, Spargo BH. Immune complex nephropathy in MCTD. Am J Med 63: 534-541, 1977.

6) Satoh K, Imai H, Yasuda T, Wakui H, Miura AB, Nakamoto Y. Sclerodermatous renal crisis in a patient with MCTD. Am J Kidney Dis 24: 215218, 1994.

7) Kuwana M, Suzuki H, Takayama S, Tominaga N. Accelerated hypertension in a patient with mixed connective tissue disease. J Rheumatol 19: 826-828, 1992 (letter).

8) Kasukawa R, Tojo T, Miyawaki S, et al. Mixed connective tissue disease -a preliminary diagnostic criteria. Jpn J Rheumatol 1: 263-270, 1988.

9) Yock PG, Popp RL. Noninvasive estimation of right ventricular systolic pressure by Doppler ultrasound in patients with tricuspid regurgitation. Circulation 70: 657-662, 1984.

10) Chan KL, Currie PJ, Seward JB, Hagler DJ, Mair DD, Tajik AJ. Comparison of three Doppler ultrasound methods in the prediction of pulmonary artery pressure. J Am Coll cardiol 9: 549-554, 1987.

11) Steen VD, Medsger TA, Osial TA, Ziegler GL, Shapiro AP, Rodnan GP. Factor predicting development of renal involvement in progressive systemic sclerosis. A J Med 76: 779-786,1984.

12) Watanabe R, Tatsumi K, Uchiyama $T$, et al. Puerperal secondary pulmonary hypertension in a patient with mixed connective tissue disease. Nippon Kyobu Shikkan Gakkai Zasshi 33: 883-887, 1995.

13) Lundberg I, Hedfors E. Pregnancy outcome in patients with high titer anti-RNP antibodies. A retrospective study of 40 pregnancies. J Rheumatol 18: 359-362, 1991.

14) Lopez-Ovejero JA, Saal SD, D’Angelo WA, Cheigh JS, Stenzel KH. Laragh JH. Reversal of vascular and renal crises of scleroderma by oral angiotensin-converting enzyme blockade. N Engl J Med 300: 1417-1419, 1979.

15) Salerni R, Rodnan GP, Leon DF, Shaver JA. Pulmonary hypertension in the CREST syndrome varient of progressive systemic sclerosis (Scleroderma). Ann Intern Med 86: 394-399, 1977.

16) Hosoda Y, Suzuki Y, Takano M, Tojo T, Homma M. Mixed connective tissue disease with pulmonary hypertension -A clinical and psthological study. J Rheumatol 14: 826-830, 1987.

17) Dahl M, Chalmers A, Wade J, Calverley D, Munt B. Ten year survival of a patient with advanced pulmonary hypertension and mixed connective tissue disease treated with immunosuppressive therapy. J Rheumatol 19: 1807-1809, 1992.

18) Friedman DM, Mitnick HJ, Danilowicz D. Recovery from pulmonary hypertension in an adolescent with mixed connective tissue disease. Ann Rheum Dis 51: 1001-1004, 1992.

19) Sawai T, Murakami K, Kurasono Y. Morphometric analysis of the kidney lesions in mixed connective tissue disease (MCTD). Tohoku J Exp Med 174: 141-154, 1994. 